\title{
Video Article \\ Characterizing Cellular Proteins with In-cell Fast Photochemical Oxidation of Proteins
}

\author{
Emily E. Chea ${ }^{1}$, Aimee Rinas ${ }^{2}$, Jessica A. Espino ${ }^{1}$, Lisa M. Jones ${ }^{1}$ \\ ${ }^{1}$ Department of Pharmaceutical Sciences, University of Maryland Baltimore \\ ${ }^{2}$ AlT Bioscience
}

Correspondence to: Lisa M. Jones at ljones@rx.umaryland.edu

URL: https://www.jove.com/video/60911

DOI: doi:10.3791/60911

Keywords: Biochemistry, Issue 157, Fast Photochemical Oxidation of Proteins (FPOP), protein footprinting, hydroxyl radicals, proteome wide structural biology, proteomics, mass spectrometry, single cell flow system

Date Published: 3/11/2020

Citation: Chea, E.E., Rinas, A., Espino, J.A., Jones, L.M. Characterizing Cellular Proteins with In-cell Fast Photochemical Oxidation of Proteins. J. Vis. Exp. (157), e60911, doi:10.3791/60911 (2020).

\section{Abstract}

Fast photochemical oxidation of proteins (FPOP) is a hydroxyl radical protein footprinting method used to characterize protein structure and interactions. FPOP uses a $248 \mathrm{~nm}$ excimer laser to photolyze hydrogen peroxide producing hydroxyl radicals. These radicals oxidatively modify solvent exposed side chains of 19 of the 20 amino acids. Recently, this method has been used in live cells (IC-FPOP) to study protein interactions in their native environment. The study of proteins in cells accounts for intermolecular crowding and various protein interactions that are disrupted for in vitro studies. A custom single cell flow system was designed to reduce cell aggregation and clogging during IC-FPOP. This flow system focuses the cells past the excimer laser individually, thus ensuring consistent irradiation. By comparing the extent of oxidation produced from FPOP to the protein's solvent accessibility calculated from a crystal structure, IC-FPOP can accurately probe the solvent accessible side chains of proteins.

\section{Video Link}

The video component of this article can be found at https://www.jove.com/video/60911/

\section{Introduction}

Hydroxyl radical protein footprinting (HRPF) is a method that probes the solvent accessibility of a protein through covalent modifications produced from hydroxyl radicals. When protein structure or protein interactions change, it will alter the solvent exposure of amino acids, thus altering the extent of modification of residues. With HRPF, protein interactions $s^{1,2,3}$ and protein conformational changes ${ }^{4,5,6}$ have successfully been interrogated in vitro. There are several methods that generate hydroxyl radicals for HRPF experiments, one being fast photochemical oxidation of proteins (FPOP). FPOP was developed by Hambly and Gross in 2005 and utilizes a $248 \mathrm{~nm}$ excimer laser to produce hydroxyl radicals through the photolysis of hydrogen peroxide $\left(\mathrm{H}_{2} \mathrm{O}_{2}\right)^{7}$.

Recently, Espino et al. extended the use of FPOP to probe protein structure in live cells, a method termed in-cell FPOP (IC-FPOP) ${ }^{8}$. In contrast to in vitro studies, studying proteins in cells accounts for molecular crowding along with various protein interactions that could potentially influence structure. Additionally, it presents the advantage of providing a snapshot of the full proteome potentially providing structural information of numerous systems at once to perform proteome wide structural biology. Furthermore, this technique is ideal for proteins that are difficult to study in vitro, like membrane proteins.

Initial studies of IC-FPOP successfully probed 105 proteins ranging in protein abundance and cellular localization. To improve the IC-FPOP method, Rinas et al. developed a microflow system for single cell flow ${ }^{9}$. The enhancement of the original flow system limits cell aggregation and increases the available $\mathrm{H}_{2} \mathrm{O}_{2}$ available for irradiation. In the initial flow system, cells clumping in the silica tubing resulted in clogs and uneven irradiation. The incorporation of two streams of a sheath buffer hydrodynamically focuses the cells, allowing them to flow individually past the laser. The incorporation of a separate syringe for the $\mathrm{H}_{2} \mathrm{O}_{2}$ enables more controlled and optimizable exposure time allowing higher $\mathrm{H}_{2} \mathrm{O}_{2}$ concentrations without adverse effects. Also, limiting the incubation time limits the breakdown of $\mathrm{H}_{2} \mathrm{O}_{2}$ by endogenous catalase. By incorporating this new flow system, the detected number of proteins with an FPOP modification increased 13-fold, thus expanding the capabilities of this method to probe a multitude of proteins in living cells. In this protocol a general IC-FPOP experiment is described focusing on the assembly of the IC-FPOP flow system. 


\section{Protocol}

\section{Set up IC-FPOP flow system}

1. To begin the assembly of the flow system, cut the fused silica using a cleavage stone to size. The IC-FPOP flow system requires four $12 \mathrm{~cm}$ and one $17 \mathrm{~cm}$ fused silica with an inner diameter (ID) of $450 \mu \mathrm{m}$ and outer diameter (OD) of $670 \mu \mathrm{m}$, two $24 \mathrm{~cm}$ and one $40 \mathrm{~cm}$ with an ID of $75 \mu \mathrm{m}$ and an OD of $360 \mu \mathrm{m}$, and finally two $57 \mathrm{~cm}$ with an ID of $150 \mu \mathrm{m}$ and an OD of $360 \mu \mathrm{m}$.

NOTE: When cutting the silica tubing, gently scrape away the polyimide coating, and bend to get the cleanest cut. Check to make sure it is a straight cut (this is necessary to ensure no blockages or leaks form).

2. Set up 15 connections using nano-tight sleeves $\left(0.0155^{\prime \prime}\right.$ ID X 1/16" OD for $360 \mu \mathrm{m}$ OD silica tubing and 0.027" ID X 1/16" OD for the 670 $\mu \mathrm{m}$ OD silica tubing) with super flangeless nut PEEK 1/4-28 flat-bottom for 1/16" OD and super flangeless ferrule w/SST ring, Tefzel (ETFE), 1/4-28 flat-bottom, for 1/16" OD. Construct connections as per the manufacturer's protocol (Figure 1).

3. Place 6 small cylindrical magnets in one $500 \mu \mathrm{L}$ syringe. Fill this syringe along with another $500 \mu \mathrm{L}$ syringe and two $5 \mathrm{~mL}$ syringes with buffer and remove air. Position on syringe pump as shown on Figure 2A.

NOTE: The $5 \mathrm{~mL}$ syringes are larger than the $500 \mu \mathrm{L}$ syringes, so a spacer is needed to tighten all the syringes simultaneously in place (Figure 2B).

4. Tighten syringe pump stopper so that the cell syringe has roughly $50 \mu \mathrm{L}$ left when the motor stalls. This will leave room for the magnetic stirrers. (Figure 2C-D).

CAUTION: If the syringe pump puts pressure on the magnets, they will jam the syringe and can cause the syringe to break.

5. Using a Luer adapter, connect a manual valve to each syringe. Assemble the silica tubing as shown in Figure 3.

NOTE: Thread the line with the cells $+\mathrm{H}_{2} \mathrm{O}_{2}$ all the way through the cross to the other side. Then insert it into the $450 \mu \mathrm{m}$ ID silica tubing. The sheath buffers in the $5 \mathrm{~mL}$ syringe will be flowing at a faster rate than the cells and $\mathrm{H}_{2} \mathrm{O}_{2}$. With the sheath buffers on both sides, the cells will be hydrodynamically focused into a single line for irradiation.

6. Position flow system next to laser. Using a lighter, burn away the silica coating on the $450 \mu \mathrm{m}$ ID tubing to make a window for laser irradiation.

7. Place a magnetic stirrer above the cell syringe containing the six magnets.

8. Set syringe pump to $492.4 \mu \mathrm{L} / \mathrm{min}$ for a final flow rate of $1,083.3 \mu \mathrm{L} / \mathrm{min}$. Flow buffer through the system three times to flush the system and test for any leaks.

9. Focus the excimer laser onto the silica tubing using a convex lens. Once focused, test the irradiation window by placing a small piece of paper behind the silica tubing and turn the laser on. Measure the region burnt from the irradiation. Calculate the needed laser frequency by using the irradiation window and flow rate to obtain an exclusion fraction of zero.

NOTE: The recommended laser energy for an IC-FPOP experiment is $\geq 120 \mathrm{~mJ}$. To get an exclusion fraction of 0 with an irradiation window of $2.58 \mathrm{~mm}$ and a flow rate of $1083.3 \mu \mathrm{L} / \mathrm{min}$, the frequency needs to be 44 . Below are the equations that are needed to calculate the laser frequency if the irradiation window, flow rate, and exclusion fraction is known.

Equation 1: $w=\pi^{*} x^{*} 100,000 *\left(y * 5 * 10^{-5}\right)^{2}$

Equation $2: v=\frac{w}{((1-b) * 1000)}$

Equation $3: f=\frac{a}{60^{*} v}$

where $\mathrm{w}$ is the volume in $\mathrm{nL}, \mathrm{x}$ is the laser spot width in $\mathrm{mm}, \mathrm{y}$ is the silica tubing ID in $\mu \mathrm{m}, \mathrm{v}$ is the total volume in $\mu \mathrm{L}, \mathrm{b}$ is the exclusion fraction, $a$ is the flow rate in $\mu \mathrm{L} / \mathrm{min}$, and $\mathrm{f}$ is the frequency in $\mathrm{Hz}$.

\section{Make quench and $\mathrm{H}_{2} \mathrm{O}_{2}$}

1. Make quench containing $100 \mathrm{mM} \mathrm{N}$-tert-Butyl-alpha-phenylnitrone (PBN) and $100 \mathrm{mM} \mathrm{N}, \mathrm{N}^{\prime}$-dimethylthiourea (DMTU). Aliquot $11 \mathrm{~mL}$ of quench for each sample into a $50 \mathrm{~mL}$ conical tube.

2. Dilute $\mathrm{H}_{2} \mathrm{O}_{2}$ to $200 \mathrm{mM}$. Each sample requires $500 \mu \mathrm{L}$ of $\mathrm{H}_{2} \mathrm{O}_{2}$.

NOTE: The quench can be made the day before and stored at $4{ }^{\circ} \mathrm{C}$ overnight, protected from light. $\mathrm{H}_{2} \mathrm{O}_{2}$ should be made fresh the day of experimentation.

\section{Collect cells}

1. Grow cells in a T175 flask to about $70-90 \%$ confluency.

2. Remove media and rinse with buffer. NOTE: Typical buffers to use are cell culture grade Dulbecco's phosphate-buffered saline (DPBS) or Hank's balanced salt solution (HBSS).

3. Detach cells using either trypsin-EDTA or with a scraper.

4. Once detached resuspend in $10 \mathrm{~mL}$ of buffer and count the cells.

5. Spin down, remove the buffer and trypsin-EDTA, and resuspend to make $2 \times 10^{6}$ cells $/ \mathrm{mL}$.

6. Aliquot $500 \mu \mathrm{L}$ of the cells per sample. NOTE: For each condition, make a minimum of 3 laser samples, and 3 no laser controls.

\section{Performing IC-FPOP}

1. Fill the two $5 \mathrm{~mL}$ syringes with buffer, the $500 \mu \mathrm{L}$ syringe containing the magnets with the cells, and the final $500 \mu \mathrm{L}$ syringe with $\mathrm{H}_{2} \mathrm{O}_{2}$. Turn the magnetic stirrer on. 
2. Spike in $220 \mu \mathrm{L}$ of dimethyl sulfoxide (DMSO) to one aliquot of quench, gently mix, and place behind flow system to collect irradiated samples. The addition of DMSO will inhibit endogenous methionine sulfoxide reductase.

3. Turn on laser, wait $7 \mathrm{~s}$, and then turn on flow system.

4. Once the sample finishes flowing, turn the laser off, and gently mix the quench with the collected sample. Place this to the side during steps 4.5 and 4.6 .

5. Fill all four syringes with the buffer the cells are suspended in and flow it through the flow system.

6. After the system finishes flushing, repeat steps 4.1 and 4.2. Start the flow without irradiation. This is the no laser control to account for background oxidation in the cells.

7. While the next sample is running, spin down the previous sample at $450-800 \times g$ for $5 \mathrm{~min}$, remove the solvent, and resuspend in $100 \mu \mathrm{L}$ of a cell lysis buffer like radioimmunoprecipitation assay (RIPA) buffer.

8. Transfer the sample to a microcentrifuge tube and flash freeze in liquid nitrogen.

9. When all samples have finished running, disassemble the flow system for cleaning. Discard the used silica tubing and clean all the other connections by sonicating for $1 \mathrm{~h}$ in $50 \%$ water: $50 \%$ methanol. Clean the syringes as per manufacturer's instructions.

\section{Digest}

1. Digest the whole cell lysate. Begin by thawing the samples and heat at $95{ }^{\circ} \mathrm{C}$ for $10 \mathrm{~min}$.

2. After heating, cool the lysate on ice for $15 \mathrm{~min}$.

3. Add 25 units of nuclease to digest DNA and RNA and incubate at room temperate for $15 \mathrm{~min}$.

4. Spin samples using a table-top centrifuge at $16,000 \times \mathrm{g}$ for $10 \mathrm{~min}$ at $4{ }^{\circ} \mathrm{C}$.

5. Collect the supernatant and transfer it to a clean microcentrifuge tube.

6. Check the protein concentration using a protein assay kit.

7. Transfer $20-100 \mu \mathrm{g}$ of sample to a clean microcentrifuge tube and bring to $100 \mu \mathrm{L}$.

8. Reduce samples with $20 \mathrm{mM}$ dithiothreiotol (DTT) at $50^{\circ} \mathrm{C}$ for $45 \mathrm{~min}$.

9. Cool the samples at room temperature for $15 \mathrm{~min}$.

10. Alkylate with $20 \mathrm{mM}$ iodoacetamide (IAA) at room temperature for 20 min protected from light.

11. Add pre-chilled acetone at a 1:4 ratio protein: acetone. Mix samples and place in $-20^{\circ} \mathrm{C}$ overnight.

12. The next morning, spin samples at $16,000 \times g$ for $10 \mathrm{~min}$ at $4{ }^{\circ} \mathrm{C}$

13. Remove the supernatant and add $50 \mu \mathrm{L}$ of $90 \%$ pre-chilled acetone. Mix samples and spin down at $16,000 \times g$ for $5 \mathrm{~min}$ at $4{ }^{\circ} \mathrm{C}$

14. Remove acetone and let samples dry by leaving the caps of the microcentrifuge open with a lint free wipe covering the top. After the samples have dried, resuspend protein pellet with $10 \mathrm{mM}$ Tris buffer $\mathrm{pH} 8$.

15. Resuspend $20 \mu \mathrm{g}$ of trypsin in $40 \mu \mathrm{L}$ of $10 \mathrm{mM}$ Tris buffer $\mathrm{pH}$ 8. Add $2 \mu \mathrm{g}$ of trypsin (mass: mass ratio of 1 trypsin: 50 sample). Incubate samples at $37^{\circ} \mathrm{C}$ overnight.

16. The next morning check the peptide concentration using a peptide assay. After the sample has been removed for the peptide assay, quench the trypsin digestion by adding formic acid to the samples (final concentration is $5 \%$ formic acid).

17. Once final peptide concentration is determined, transfer $10 \mu \mathrm{g}$ of each sample to a clean microcentrifuge tube. This ensures the same amount of each sample is analyzed. Dry the sample using a vacuum centrifuge. Once dried resuspend with $20 \mu \mathrm{L}$ of mass spectrometry grade $0.1 \%$ formic acid. Transfer samples to autosampler vials.

\section{Liquid Chromatography-Tandem Mass Spectrometry}

1. To localize FPOP modifications analyze the digested cell lysate using LC-MS/MS analysis.

2. Use mobile phases of $0.1 \%$ formic acid in water $(A)$ and $0.1 \%$ formic acid in acetonitrile (B)

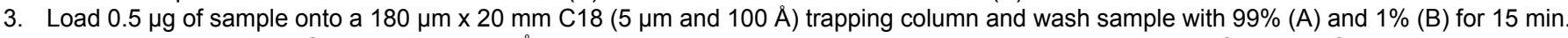

4. Using a $75 \mu \mathrm{m} \times 30 \mathrm{~cm} \mathrm{C18}(5 \mu \mathrm{m}$ and $125 \AA)$ analytical column, run the analytical separation method with a flow rate of $0.300 \mu \mathrm{L} / \mathrm{min}$ starting at $3 \%(B)$ for one min then ramp to $10 \%$ (B) from 1-2 min. Next ramp to $45 \%$ (B) from $2-100$ min then $100 \%$ (B) from $100-110 \mathrm{~min}$. Clean the column by holding at 100\% (B) from 110-115 min. Recondition the column by ramping down to $3 \%$ (B) from $115-116$ min and hold at $3 \%(B)$ from $116-130$ min.

5. Set the MS acquisition method to have a resolution of 60,000 with an $\mathrm{m} / \mathrm{z}$ scan range of $375-1500$. Set the automatic gain control (AGC) target to $5.0 \times 10^{5}$ with a maximum injection time of $50 \mathrm{~ms}$.

6. During the MS acquisition, select the precursor ions with charge states 2-6 for isolation via data dependent acquisition (DDA) with an isolation window of $1.2 \mathrm{~m} / \mathrm{z}$ and a cycle time of $4 \mathrm{~s}$. Select the peptides with an intensity threshold of $5.0 \times 10^{4}$ for HCD activation with a normalized energy set to $32 \%$. Exclude the peptides after $1 \mathrm{MS} / \mathrm{MS}$ acquisition for $60 \mathrm{~s}$. Set the MS/MS resolution to 15,000 with an AGC target of $5.0 \times$ $10^{4}$ and a maximum injection time of $35 \mathrm{~ms}$.

\section{Data Processing}

1. Search the RAW files on an available protein analysis software against a relevant protein database and the relevant digest enzyme. Here, use the Swiss-Prot Homo Sapiens database and trypsin.

2. Set the precursor mass to search between 350 to $5,000 \mathrm{Da}$ and a mass tolerance of $10 \mathrm{ppm}$. There can be at most 1 missed cleavage site with a peptide length between 6 to 144 residues. These limitations facilitate database searching.

3. Set the fragment ions maximum mass tolerance to $0.02 \mathrm{Da}$ with the carbamidomethyl $(+57.021)$ as a static modification and all FPOP modifications from 17 amino acids as a dynamic modification (Figure 4 is an example of the protein analysis workflow used to detect FPOP modifications).

NOTE: FPOP modifications on serine and threonine are not included in the search due to their lower reactivity with hydroxyl radicals.

4. Search with a decoy database with a false discovery rate of $1 \%$ and $5 \%$. 
5. Once files are finished searching calculate the extent of FPOP modification. Open Proteome Discoverer 2.2, export sequence, modification locations, protein accession, spectrum file, precursor abundance, and retention time information. Calculate the extent of modification from equation 4:

EEIC area modified

$$
\text { ¿EIC area }
$$

The EIC area modified is the chromatographic area of a specific peptide with a hydroxyl radical modification. The EIC area is the total chromatographic area of both modified and unmodified areas of that specific peptide. The extent of oxidation is calculated in the samples with and without irradiation. The sample omitting irradiation (control) accounts for any background oxidation that could have been present in the cells before and after $\mathrm{H}_{2} \mathrm{O}_{2}$ exposure. The controls are subtracted from the irradiation samples to help isolate FPOP specific modifications.

\section{Representative Results}

IC-FPOP is a footprinting method to interrogate protein interactions in live cells. In the IC-FPOP flow system, the $\mathrm{H}_{2} \mathrm{O}_{2}$ exposure time is limited to roughly $3 \mathrm{~s}$, warranting higher $\mathrm{H}_{2} \mathrm{O}_{2}$ concentrations without detrimental consequences for the cells. The flow system also incorporates two streams of sheath buffer, which hydrodynamically focuses the cells to the center of the tubing producing a single flow of cells to be uniformly irradiated (Figure 5) ${ }^{9}$. Fluorescence imaging of orthogonal YZ stacked images (Figure 5A) show a clear separation of the sheath buffer (containing a FITC fluorophore) from the cell solution (containing a TMRM fluorophore). To emphasize this separation, Figure 5B and Figure 5C show three-dimensional average heat maps of either the sheath buffer solution or cell solution, illustrating minimal mixing of the two solutions.

The use of the single cell flow system increases the number of oxidatively modified proteins by 13 -fold (Figure $6 \mathbf{A})^{9}$. In this method, proteins in many of the cellular compartments are labeled with membrane proteins, cytoplasmic proteins, and proteins within the nucleus being the most prevalent $^{8,9}$. To ensure proteins were modified within intact cells, fluorescent images of CellROX treated cells were performed following $\mathrm{H}_{2} \mathrm{O}_{2}$ treatment and irradiation (Figure $6 \mathrm{~B})^{8}$. The stability of the cells throughout the labeling process further confirms the efficacy of IC-FPOP to probe proteins in their native cellular environment. By using tandem-mass spectrometry, these modifications can be localized to specific amino acids on a protein. Figure 7 represents a modification that takes place during IC-FPOP along with its extracted ion chromatogram. The shift observed in the extracted ion chromatogram translates to the change in hydrophobicity caused by the oxidized methionine in the modified peptide.

To test if the FPOP modifications probe solvent accessibility inside the cells, in-cell labeled actin was compared to both an in vitro footprinting

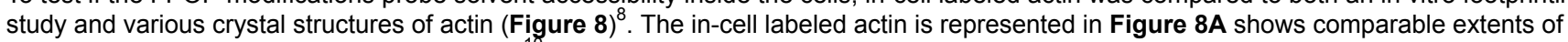
oxidation from the in vitro study by Guan et al. ${ }^{10}$ (Figure 8B), concluding actin has similar solvent accessibility for both in-cell and in vitro studies. To further confirm IC-FPOP was probing the solvent accessibility of actin, the extent of FPOP modifications were compared to the solvent accessibility of the labeled residues calculated from two actin crystal structures (Figure 8C). This correlation demonstrates that IC-FPOP probes the solvent accessibility of the monomeric protein well.
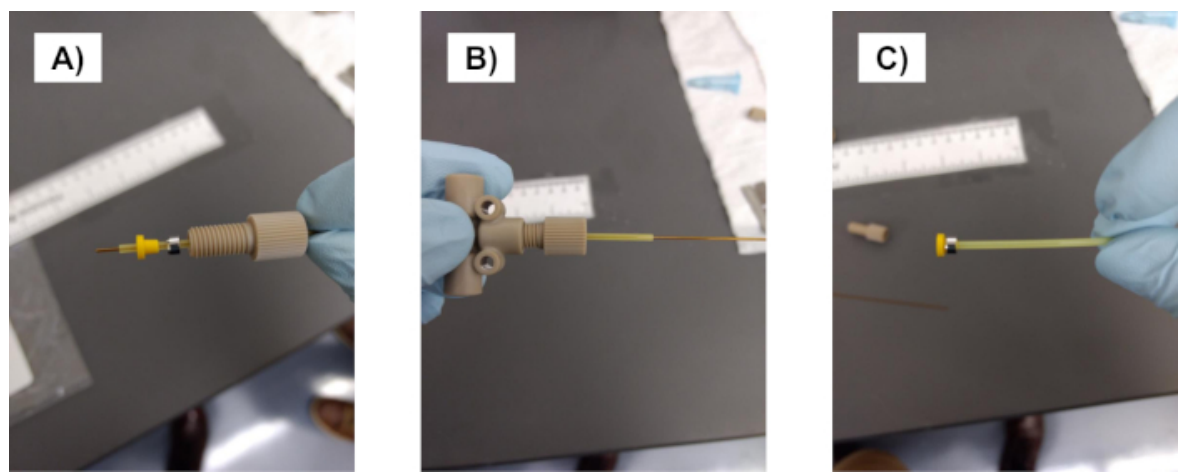

Figure 1: How to properly construct ferules. (A) Place ferrules, silica tubing, and sleeve together before tightening. (B) Tighten all components together. (C) Final product will produce a ferule that has been tightened down on the sleeve. Please click here to view a larger version of this figure. 

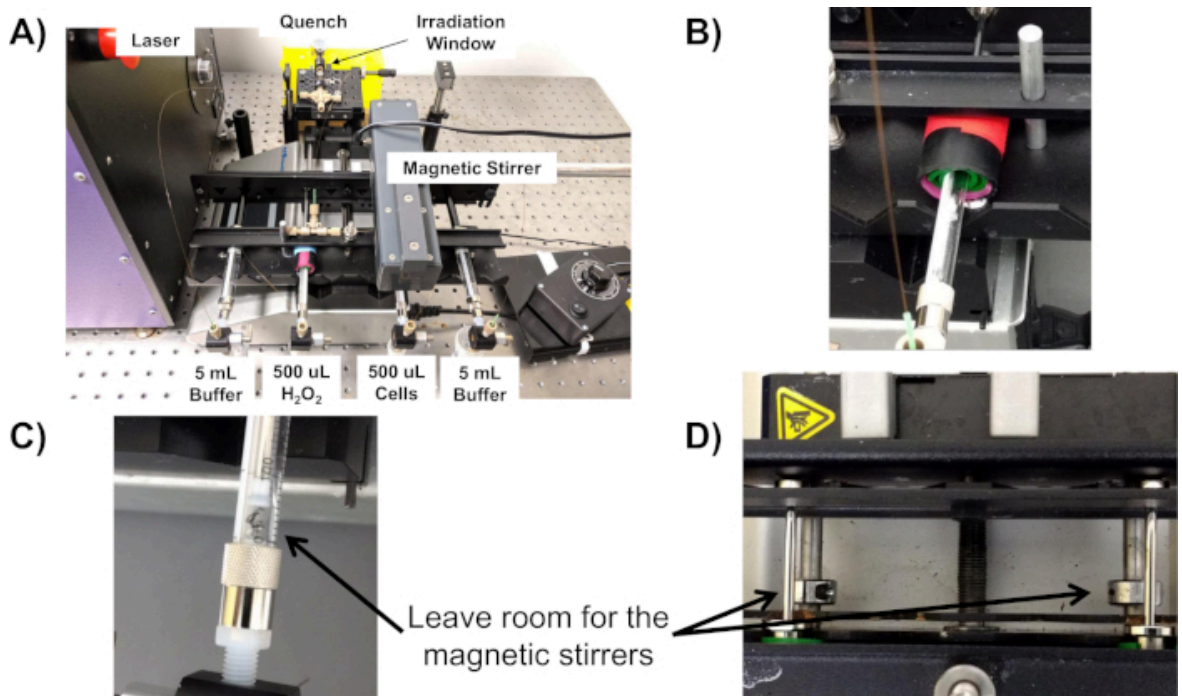

Figure 2: Setting up IC-FPOP flow system. (A) Image of a fully assembled IC-FPOP flow system positioned next to the laser. (B) Example of a spacer needed to increase the outer diameter of the $500 \mu \mathrm{L}$ syringes to successfully tighten all syringes down together. (C) Representative pictures showing the space required for the magnetic stirrers. (D) Stoppers are necessary to stall the syringe pump without breaking the syringes. Please click here to view a larger version of this figure.

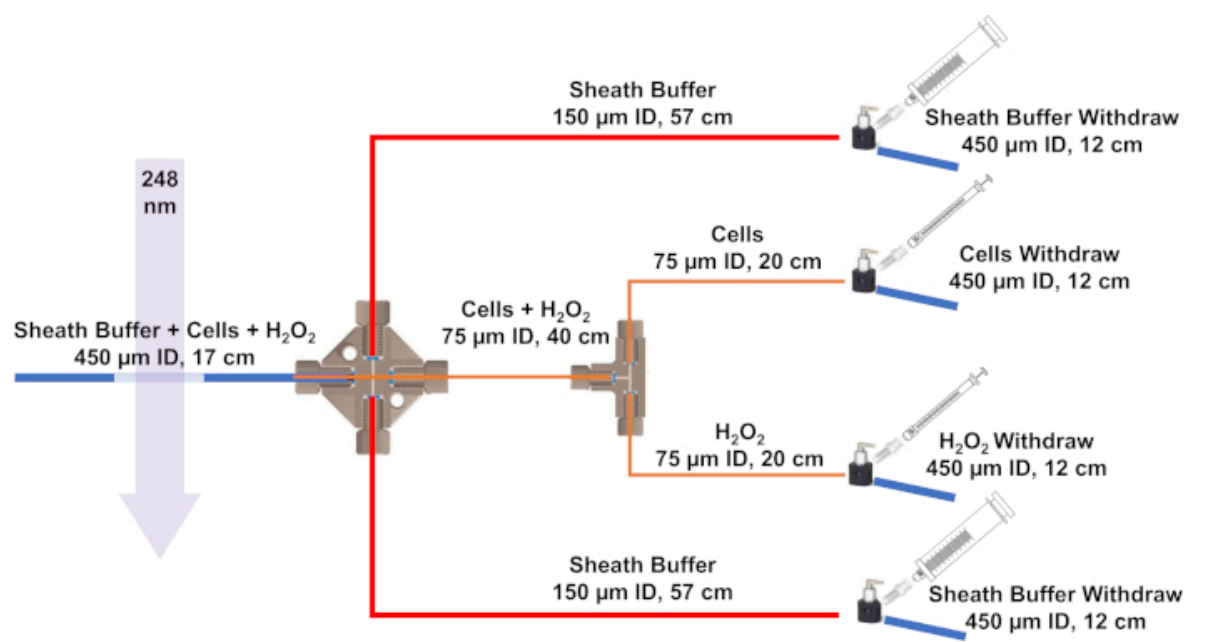

Figure 3: Schematic of the flow system developed for IC-FPOP. Blue lines represent silica tubing with a $450 \mu \mathrm{m}$ ID and $670 \mu \mathrm{m}$ OD, red lines have a $150 \mu \mathrm{m}$ ID and $360 \mu \mathrm{m}$ OD, and orange lines have a $75 \mu \mathrm{m}$ ID and $360 \mu \mathrm{m}$ OD. Please click here to view a larger version of this figure. 


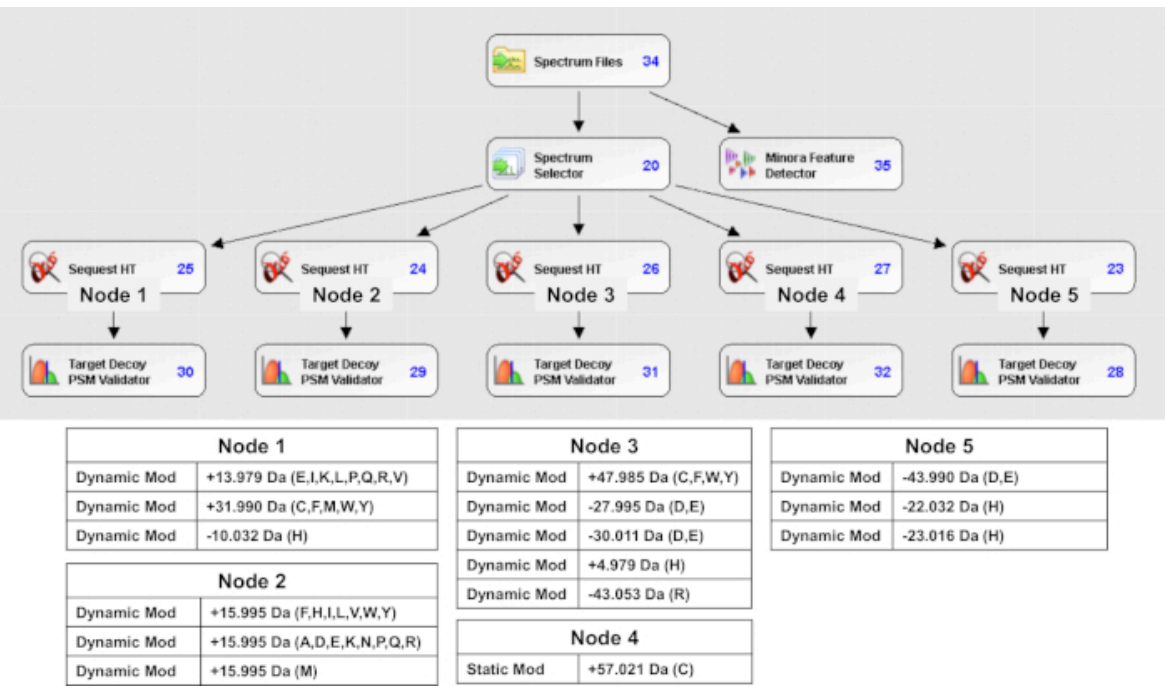

Figure 4: Protein analysis software used to detect FPOP modifications. A typical workflow with the corresponding modifications searched in each node. Please click here to view a larger version of this figure.

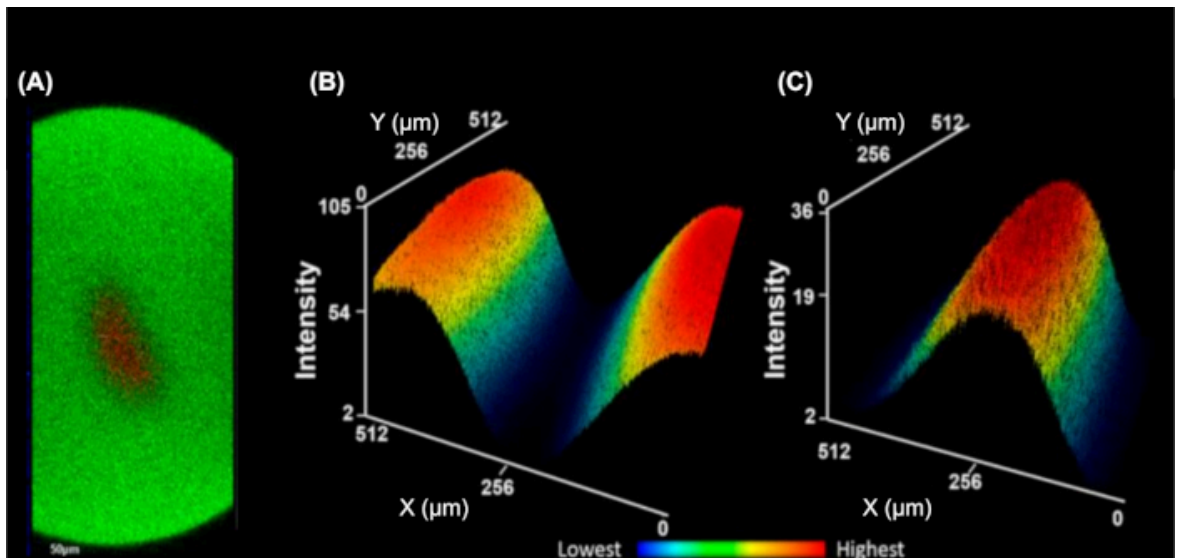

Figure 5: The single cell flow system hydrodynamically focuses the cells into a single stream. (A) Orthogonal YZ stack illustrating 3D focusing of the cellular analyte (red, TMRM fluorophore) surrounded by the sheath buffer (green, FITC fluorophore). Three-dimensional average intensity heat map of the sheath buffer (B) and cellular analyte (C). Lower intensities are blue and highest are red (B-C). This figure has been modified from Rinas et al. ${ }^{9}$ Please click here to view a larger version of this figure.

A)

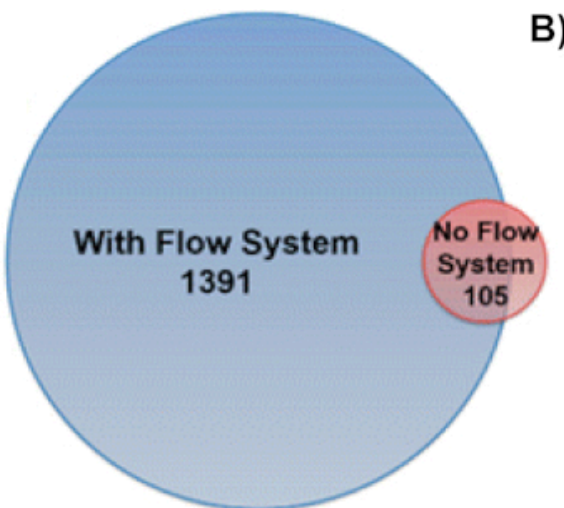

B)

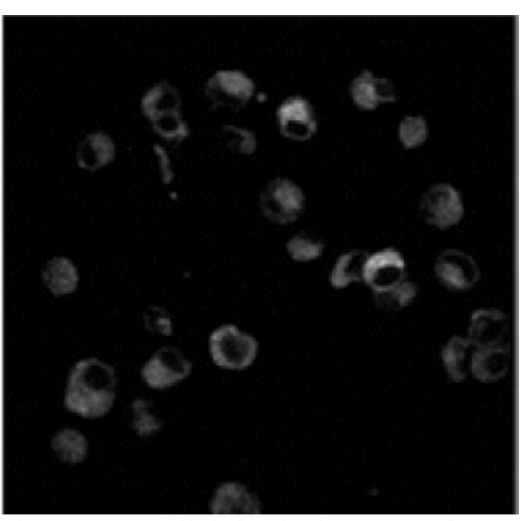

Figure 6: Utilization of the IC-FPOP Flow System drastically increases FPOP modified proteins in intake cells. (A) Comparison of oxidized proteins identified with and without the flow system. The flow system identified 1391 FPOP modified proteins while only 105 proteins were identified with no flow system with an overlap of 58 modified proteins. This figure has been modified from Rinas et al. ${ }^{9}$ (B) Fluorescence imaging of CellROX treated cells after IC-FPOP show the cells are still intact after oxidative labeling. Cells were imaged using an Olympus Fluoview FV1000 MPE multiphoton microscope at $665 \mathrm{~nm}$. Image shown is a single slice. This figure has been modified from Espino et al. ${ }^{8}$ Please click here to view a larger version of this figure. 

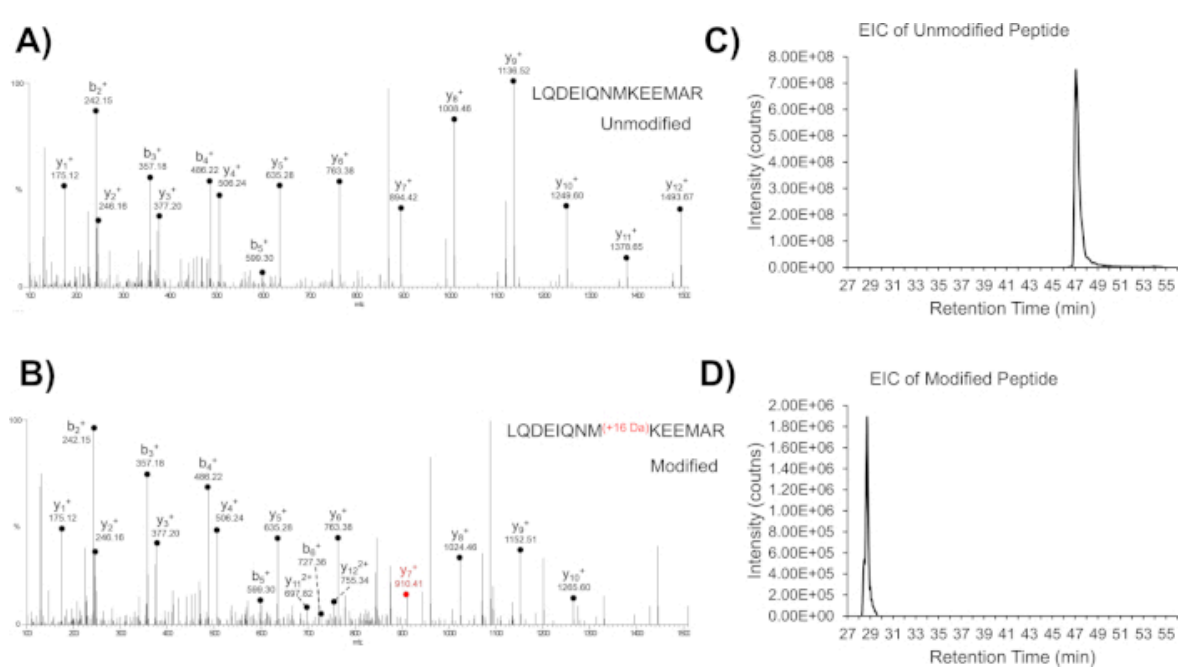

Figure 7: Examples of tandem MS/MS spectra that take place during IC-FPOP. Product-ion (MS/MS) spectra of an (A) unmodified peptide, and an (B) oxidation detected on residue M8 found on that peptide. A representative EIC of the (C) unmodified peptide and (D) modified peptide. Please click here to view a larger version of this figure.
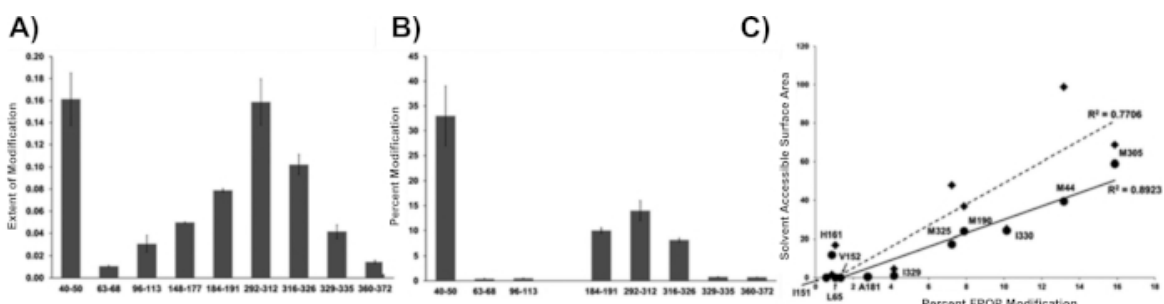

Figure 8: IC-FPOP is effective in probing the solvent accessibility of proteins. (A) Extent of modification for the 9 oxidatively modified peptides from actin. Values are shown as averages plus and minus standard deviation $(n=3)$. (B) Modification of actin peptides oxidized in vitro by synchrotron radiolysis from Guan et al. ${ }^{10}$ (C) Correlation of residue FPOP modifications with SASA in the tight (triangles, dashed trend line) and open (circles, solid trend line) states of actin. This figure has been modified from Espino et al. ${ }^{8}$ Please click here to view a larger version of this figure.

\section{Discussion}

Several mass spectrometry-based techniques have been developed to study protein structure and protein-ligand complexes in a proteomewide manner in whole cells or cell lysates. These techniques include but are not limited to stability of proteins from rate of oxidation (SPROX), thermal proteome profiling (TPP), chemical cross-linking (XL-MS), and hydroxyl radical protein footprinting (HRPF). Each technique has unique limitations and advantages compared to one another, which have been extensively reviewed ${ }^{12}$. Each of these methods have been used for proteome wide structural biology to elucidate protein structure and ultimately function within the complex cellular environment. IC-FPOP is a HRPF technique that utilizes hydroxyl radicals to oxidatively modify solvent exposed side chains of amino acids, probing protein structure and protein-ligand interactions within viable cells ${ }^{13}$. IC-FPOP is an improvement to initial HRPF in live cells that used Fenton chemistry to generate radicals on the minutes timescale ${ }^{14}$. In this study, structural changes in an integral membrane protein in response to lowering the $\mathrm{pH}$ or ionic strength of the buffer were successfully characterized with good oxidation coverage across the protein. Compared to Fenton chemistry, IC-FPOP is much faster, modifying proteins on the microsecond timescale, thus enabling the native protein conformation to be studied.

A key test for IC-FPOP is to confirm the viability of the cells following exposure to $\mathrm{H}_{2} \mathrm{O}_{2}$. Using a $40 \mathrm{~cm}$ mixing line, the cells are incubated in $\mathrm{H}_{2} \mathrm{O}_{2}$ for roughly $3 \mathrm{~s}$ before irradiation. This time can be adjusted by changing the length of this silica tubing. It is noteworthy that although the use of trypan blue to test cell viability shows the integrity of the cells are sustained following $\mathrm{H}_{2} \mathrm{O}_{2}$ incubation, the cells could potential be under stress effecting signaling pathways that interact with $\mathrm{H}_{2} \mathrm{O}_{2}$. Fortunately, the short incubation time is faster than protein synthesis providing confidence the proteins present are not induced by $\mathrm{H}_{2} \mathrm{O}_{2}$.

The next important step is to confirm proper assembly of the flow system. Once assembled, ensure there are no leaks present after flushing the system with the desired buffer. If leaks are present, make sure that the silica tubing was cut properly and is flush against the ferrule to make a proper seal once tightened down. All parts are hand-tightened, so no tools are necessary. During each IC-FPOP experiment, make sure that the magnetic stirrers in the cell syringe remain in motion. This small agitation limits the number of cells that settle at the bottom of the syringe but is not harsh enough to shear the cells. After one run, there is roughly $50 \mu \mathrm{L}$ of cells left in the syringe. Always make sure to dilute this out with a rinsing step to limit the number of cells that carry over to the next experiment. It is recommended to use a fresh cell syringe if multiple cell treatments are being compared. It is also important to select an appropriate buffer for the cells being tested. Some buffers quench the hydroxyl radical leading to fewer modifications on proteins. Xu et al. have shown that some commonly used buffers decrease the hydroxyl radical lifetime ${ }^{11}$. DPBS and HBSS are common buffers used for IC-FPOP experiments.

Following IC-FPOP, optimize the digestion protocol based on the parameters needed. Since FPOP produces irreversible covalent modifications, there is ample time available for a thorough digestion and clean-up without losing the labeling coverage. Always test and normalize the protein 
concentration so uniform peptide concentrations are loaded for tandem mass spectrometry. Finally, be mindful that an immunoprecipitation cannot be performed in conjunction with IC-FPOP. If an FPOP modification targets the region of interaction the affinity of the antibody will be lowered. To help increase the identification of FPOP modifications, 2D-chromatographic separation steps have shown to more than triple the number of oxidized peptides detected ${ }^{15}$.

A challenge of any FPOP experiment is the complicated level of data analysis due to the possible oxidation products that can arise. This is true for both in-cell or in vitro but is drastically increased with the added complexity of analyzing cell lysates. With further optimization of ICFPOP more proteins with higher modification coverages are arising, thus expeditiously making analysis more arduous. The shear amount of data generated from a single IC-FPOP experiment limits the use of manual validation causing researchers to rely more heavily on software. Due to this, Rinas et al. developed a quantitation strategy for HRPF using Proteome Discoverer (PD) ${ }^{16}$. This method utilizes a multi-search node workflow on PD combined with a quantitative platform in a spreadsheet. Further improvements on the IC-FPOP platform are underway to increase the number of identified peptides with FPOP modifications along with increased reproducibility and quantitation accuracy.

\section{Disclosures}

Lisa Jones is an inventor on the flow assembly for cells patent (publication number: 20180079998).

\section{Acknowledgments}

This work was supported by the NSF CAREER Award (MCB1701692) for LMJ.

\section{References}

1. Gau, B., Garai, K., Frieden, C., Gross, M. L. Mass spectrometry-based protein footprinting characterizes the structures of oligomeric apolipoprotein E2, E3, and E4. Biochemistry. 50 (38), 8117-8126 (2011).

2. $\mathrm{Li}, \mathrm{Z}$. et al. High structural resolution hydroxyl radical protein footprinting reveals an extended Robo1-heparin binding interface. Journal of Biological Chemistry. 290 (17), 10729-10740 (2015).

3. Zhang, H., Gau, B. C., Jones, L. M., Vidavsky, I., Gross, M. L. Fast photochemical oxidation of proteins for comparing structures of proteinligand complexes: the calmodulin-peptide model system. Analytical Chemistry. 83 (1), 311-318 (2010).

4. Jones, L. M. et al. Complementary MS methods assist conformational characterization of antibodies with altered S-S bonding networks. Journal of the American Society for Mass Spectrometry. 24 (6), 835-845 (2013).

5. Kiselar, J. G., Janmey, P. A., Almo, S. C., Chance, M. R. Structural analysis of gelsolin using synchrotron protein footprinting. Molecular \& Cellular Proteomic. 2 (10), 1120-1132 (2003).

6. Vahidi, S., Stocks, B. B., Liaghati-Mobarhan, Y., Konermann, L. Mapping pH-induced protein structural changes under equilibrium conditions by pulsed oxidative labeling and mass spectrometry. Analytical Chemistry. $\mathbf{8 4}$ (21), 9124-9130 (2012).

7. Hambly, D. M., Gross, M. L. Laser flash photolysis of hydrogen peroxide to oxidize protein solvent-accessible residues on the microsecond timescale. Journal of the American Society for Mass Spectrometry. 16 (12), 2057-2063 (2005).

8. Espino, J. A., Mali, V. S., Jones, L. M. In cell footprinting coupled with mass spectrometry for the structural analysis of proteins in live cells. Analytical Chemistry. 87 (15), 7971-7978 (2015).

9. Rinas, A., Mali, V. S., Espino, J. A., Jones, L. M. Development of a Microflow System for In-Cell Footprinting Coupled with Mass Spectrometry. Analytical Chemistry. 88 (20), 10052-10058 (2016).

10. Guan, J.-Q., Almo, S. C., Reisler, E., Chance, M. R. Structural Reorganization of Proteins Revealed by Radiolysis and Mass Spectrometry: G-Actin Solution Structure Is Divalent Cation Dependent. Biochemistry. 42 (41), 11992-12000 (2003).

11. Xu, G., Chance, M. R. Hydroxyl radical-mediated modification of proteins as probes for structural proteomics. Chemical Reviews. 107 (8), 3514-3543 (2007).

12. Kaur, U. et al. Proteome-Wide Structural Biology: An Emerging Field for the Structural Analysis of Proteins on the Proteomic Scale. Journal of Proteome Research. 17 (11), 3614-3627 (2018).

13. Chea, E. E., Jones, L. M. Analyzing the structure of macromolecules in their native cellular environment using hydroxyl radical footprinting Analyst. 143 (4), 798-807 (2018)

14. Zhu, Y. et al. Elucidating in vivo structural dynamics in integral membrane protein by hydroxyl radical footprinting. Molecular \& Cellular Proteomic. 8 (8), 1999-2010 (2009).

15. Rinas, A., Jones, L. M. Fast photochemical oxidation of proteins coupled to multidimensional protein identification technology (MudPIT): expanding footprinting strategies to complex systems. Journal of the American Society for Mass Spectrometry. 26 (4), $540-546$ (2015).

16. Rinas, A., Espino, J. A., Jones, L. M. An efficient quantitation strategy for hydroxyl radical-mediated protein footprinting using Proteome Discoverer. Analytical and Bioanalytical Chemistry. 408 (11), 3021-3031 (2016). 